\title{
De la crisis del régimen neo-desarrollista y la hegemonía kirchnerista al triunfo de Cambiemos
}

\section{From the crisis of the neo-developmentalist regime and the Kirchnerist hegemony to the triumph of Cambiemos}

\section{Gastón Varesi}

Gastón Varesi es docente en la Universidad Nacional de La Plata e Investigador Asistente deL Consejo Nacional de Investigaciones Científicas y Técnicas, Argentina.

E-mail: gastonvaresi@hotmail.com

\section{resumen}

En 2015, Cambiemos derrotó al kirchnerismo, accediendo al gobierno nacional y estableciendo un punto de inflexión. El artículo se pregunta ¿cuáles fueron las tensiones que hicieron posible aquel resultado, tanto a nivel del régimen neodesarrollista como de la construcción hegemónica en que se sustentaba? Para responder a este interrogante nos proponemos indagar acerca del cambio de relaciones de fuerzas, desde un enfoque multi-dimensional y multi-escalar, identificando los factores de crisis en los planos de la acumulación y de la hegemonía, visualizando distintos límites y contradicciones que coadyuvaron al desgaste del proyecto que dirigió la Argentina entre 2003 y 2015. Partimos de un análisis de tres núcleos claves del proceso de acumulación: las políticas, las variables económicas y las fracciones de clase; daremos cuenta de la conformación de distintos desequilibrios como la persistente inflación, la crisis energética, la reticencia inversora, la fuga de capitales, entre otros, que fueron erosionando las cuentas públicas y externas, en un contexto de alta extranjerización y concentración que favoreció la capacidad de veto del gran capital sobre las iniciativas del kirchnerismo. Asimismo, abordaremos distintos aspectos de la estrategia hegemónica de esta fuerza, su potencia, límites y desgaste, con el fin de gestar una lectura integradora del período estudiado.

\section{palabras clave}

régimen neo-desarrollista / modelo productivoexportador / hegemonía kirchnerista / relaciones de fuerzas / Argentina

\section{summary}

In 2015, Cambiemos defeated the Kirchnerism, reaching the national government and establishing a turning point. This article seeks to understand what were the tensions, both at the level of the neo-developmentalist regime and the hegemonic construction on which it was based, that made that result possible. To do this, we propose to investigate the change of relations of force, from a multi-dimensional and multi-scalar approach, identifying the factors of crisis in the facets of accumulation and hegemony, in order to visualize different limits and contradictions that contributed to the erosion of the project that led Argentina between 2003 and 2015. Based on an analysis of the three key cores of the accumulation process: policies, economic variables and class fractions, we will account for the formation of different imbalances such as the persistent inflation, the energy crisis, investment reticence, capital outflow, among others, that were eroding public and external accounts, in a context of high foreignization and concentration that favored the veto capacity of big capital on the initiatives of Kirchnerism. Likewise, we will approach different aspects of the hegemonic strategy of this force, its potency, limits and weathering, in order to create an integrative reading on the period of study.

\section{keywords}

neo-developmentalist regime / productiveexporter model / Kirchnerist hegemony / relations of force / Argentina 


\section{Introducción}

El presente artículo se propone como objetivo aportar distintas claves de análisis sobre los límites y tensiones irresueltas que dieron origen a elementos de crisis, tanto a nivel del régimen neo-desarrollista argentino como de la construcción hegemónica en la que se sustentaba, y que habilitaron una variación en las relaciones de fuerzas que derivó en el triunfo de la alianza Cambiemos.

En este camino, indagaremos en las dimensiones de hegemonía y acumulación, a partir de una estrategia metodológica que combina técnicas cuantitativas y cualitativas en estrecha vinculación con el enfoque teórico y los objetivos que constituyen el problema de estudio. Así, se irán articulando elementos económicos y políticos de más largo plazo que se fueron sedimentando durante el período del neodesarrollismo (2002-2015) y del kirchnerismo como fuerza político-hegemónica, junto con factores coyunturales relevantes, que nos permitan delinear algunas de las causas que posibilitaron el giro restaurador que vive actualmente Argentina. ${ }^{1}$

\section{Acumulación, hegemonía y relaciones de fuerzas}

El análisis del funcionamiento de las sociedades capitalistas contemporáneas nos convoca al desarrollo de herramientas conceptuales que, recuperando la agudeza y vigencia de los clásicos, nos permitan su actualización en el marco de las novedades históricas así como de los requisitos del propio proceso de investigación y las preguntas que guían el camino para desentrañar las relaciones fundamentales que constituyen al objeto de estudio. En este sentido, rescatamos una perspectiva de carácter holístico expresada en una estrategia de análisis multi-dimensional y multi-escalar, como requisito para abordar los movimientos complejos de nuestras sociedades pudiendo atender a esa totalidad sin dejar de conformar los conceptos que nos permitan ahondar en las profundidades de las partes que la constituyen.

En primer lugar, recuperamos la categoría gramsciana de bloque histórico, definida por una relación de reciprocidad, un movimiento dialéctico entre la estructura y las superestructuras, entendidas estas últimas como un conjunto complejo, contradictorio y discorde, que expresan el conjunto de las relaciones de producción, sin ser ellas un mero "resultado" sino un compuesto de distintos elementos políticos, jurídicos, ideológicos y culturales con entidad propia y con capacidad de incidencia sobre la dimensión estructural misma (Gramsci, 2003).

La estructura socio-económica de las sociedades burguesas tiene un aspecto clave en el desarrollo del proceso de acumulación del capital, en tanto establece las características del movimiento a partir del cual el capital se reproduce de forma ampliada. Como sostenía Poulantzas (1981), este proceso de reproducción ampliada del capital regenera consigo todas las relaciones sociales que le son fundamentales y es por ello también un proceso de reproducción ampliada de las clases sociales, el cual trascurre por un doble andarivel: se reproducen tanto los lugares que constituyen la estructura social como los agentes que ocupan dichas posiciones estructurales. Asimismo, Gramsci (2003) sostiene que hay un tipo de poder que emana de la propia estructura, a partir del desarrollo de las fuerzas productivas y de la posición y la función que los grupos sociales cumplen en la 
producción misma, al cual denomina como las relaciones de fuerzas sociales. Este poder de carácter económico se distribuye asimétricamente, está siempre en disputa, y define las capacidades que los distintos grupos, en virtud de su anclaje estructural, pueden ejercer tanto sobre el funcionamiento de las variables económicas como sobre el Estado para conseguir condiciones favorables a su reproducción ampliada.

Estos elementos nos llevan a interpelar el proceso de acumulación del capital a partir de tres núcleos conceptuales. En primer lugar, las variables económicas, cuya regularidad y orden de prelación, en el sentido de jerarquía explicativa e incidencia causal, como señalara Basualdo (2007), nos permiten comprender las características del funcionamiento económico de una estructura. En segundo lugar, encontramos el núcleo de los agentes económicos aglutinados en las fracciones de clase según su posición estructural y función, los cuales, como mencionamos, procuran desplegar estrategias para su propia expansión incidiendo sobre el desempeño de las distintas variables de la economía así como también sobre el tercer núcleo conceptual. Éste refiere al componente de políticas económicas, como aspecto de la acción estatal dirigido específicamente a incidir sobre el proceso de acumulación, estableciendo las reglas que definen el campo de acción de los agentes al tiempo que capturan y redistribuyen parte del excedente, determinando "ganadores" y "perdedores" según el proyecto que lidere el Estado (Varesi, 2013).

Llegamos aquí a la segunda dimensión que compone nuestra estrategia de análisis: la hegemonía, definida como la dirección política, ideológica y cultural de un grupo social sobre otra serie de grupos sociales. Entendemos que en Gramsci puede reconstruirse una genuina teoría de la hegemonía que pone el foco en la construcción y difusión de las concepciones del mundo, con un abordaje analítico que va desde el sentido común hasta las formas más elaboradas del pensamiento, y que atraviesa la conformación de valores e ideas que se materializan en prácticas, que al ser portadas por fuerzas político-sociales en su constitución hegemónica, dan formas a distintos tipos de Estado (Varesi, 2016).

La hegemonía, como capacidad de conducción, implica a su vez, una predominancia de los factores del consenso por sobre los de la coerción, siendo ambos constitutivos de toda relación política. Esta construcción de consensos supone el establecimiento de concesiones respecto de los grupos subordinados junto con una expansión de la propia visión del mundo del grupo hegemónico, de modo que su proyecto puede ser abrazado por éstos, logrando la adhesión activa o pasiva de buena parte de los subordinados, apareciendo así como la realización de un universal, del "bien común", el "desarrollo de todas las energías nacionales" como sostuviera Gramsci. Esto nos sumerge en el plano de las relaciones de fuerzas políticas, abordadas por Gramsci según el grado de homogeneidad, organización y conciencia política colectiva, partiendo de un grado económico-corporativo, en el cual priman los intereses gremiales, hasta un grado político hegemónico donde uno de los proyectos en punga avanza hacia su universalización, articulando demandas de grupos dominantes y subalternos, estableciendo consensos en una formación y superación de equilibrios inestables, "donde los intereses del grupo 
dominante prevalecen, pero hasta cierto punto, o sea, hasta el punto en que chocan con el mezquino interés económico-corporativo" (Gramsci, 2003: 58).

Ahora bien, estas múltiples dimensiones precisan, a su vez, de la distinción de múltiples escalas. En Gramsci podemos observar cómo su estrategia de análisis de situaciones comienza por el abordaje de las relaciones de fuerzas internacionales, que implican comprender las transformaciones orgánicas que caracterizan al modo de producción globalmente dominante así como la conformación de las potencias y los bloques de Estados hegemónicos, indagando su relación con las naciones y bloques menores, abriendo un espacio de reflexión sobre las dinámicas del imperialismo, los procesos de integración y las luchas por la soberanía. Luego, las relaciones de fuerzas sociales, políticas y militares, son susceptibles de ser analizadas, no sólo a escala internacional, sino también a escala nacional y local.

Para el abordaje de la dimensión estructural con eje en la acumulación de capital se presenta la misma necesidad teórica de diseñar una estrategia de análisis que dé cuenta de las múltiples escalas. En este sentido, fuimos desarrollando una distinción entre dos categorías: la de régimen de acumulación y la de modelo de acumulación (Varesi, 2013). Sin dejar de señalar la multiplicidad y diferencias de las definiciones que han sido elaboradas, rescatamos como antecedentes las propuestas de Basualdo (2007) y Torrado (1992), dando lugar a una estrategia que sintetiza el abordaje del proceso de acumulación a partir de los tres núcleos conceptuales previamente mencionados de variables económicas, políticas económicas y fracciones de clases y estableciendo una distinción de escala para ambas categorías. A nivel de la escala temporal, ligamos el régimen de acumulación al abordaje de períodos de más largo plazo, mientras que remitimos al modelo a recortes temporales más breves, constituyendo un subperíodo del régimen de acumulación. Un ejemplo sería comprender que entre 1976 y 2001 en Argentina se desarrolló un régimen de acumulación neoliberal, caracterizado por el eje de valorización financiera, con creciente liberalización económica, distintos niveles de ajuste y reforma estructural favorables a los sectores más concentrados del capital; este régimen tuvo en su interior dos modelos, el modelo liberal-corporativo de la dictadura y el modelo de la convertibilidad de los años 90, los cuales, compartiendo los grandes aspectos del régimen, en una escala de mayor especificidad, tuvieron diferencias particulares y un funcionamiento interno distintivo que les dio coherencia en sí mismos hasta su entrada en crisis. Asimismo, podemos pensar momentos dentro de un régimen de acumulación en que no se pueda delimitar la existencia de un modelo, por ejemplo, por la ausencia de regularidades significativas, como sucedió en los años 80, cuando el gobierno de Alfonsín desplegó planes de política económica que no lograron sostenerse en el tiempo, dificultando observar regularidades de mayor especificidad entre los tres núcleos, pero sin romper con las lógicas generales del régimen neoliberal entonces vigentes. Otra diferencia es la escala espacial. Mientras que un régimen de acumulación puede recubrir un amplio conjunto de formaciones sociales nacionales y ser analizado en consecuencia (por ej. el neoliberalismo en Latinoamérica), el modelo de acumulación se acota a 
una sola de ellas, ligado al rango de las políticas del Estado nacional, en virtud de su mayor especificidad (lo que volvería errado pensar, por ejemplo el modelo de la convertibilidad más allá de la frontera nacional).

\section{Régimen neo-desarrollista, modelo productivo-exportador y hegemonía kirchnerista}

El punto de partida para comprender nuestro período de estudio es la crisis de 2001. Ésta atravesó de conjunto al bloque histórico, expresando una profunda crisis política, ideológica y cultural en el plano de la hegemonía al tiempo que en el plano de la acumulación derivó en el colapso del modelo de la convertibilidad, que había sido la expresión más acabada del régimen neoliberal en Argentina.

\subsection{Diez factores para caracterizar el neo-desarrollismo y su impacto en las relaciones de fuerzas sociales}

La crisis del neoliberalismo dio lugar a un nuevo régimen de acumulación neodesarrollista, del cual podemos destacar, a modo de síntesis, un conjunto de rupturas que le dieron sus rasgos principales.

En primer lugar, se inició una política de tipo de cambio competitivo, la cual tuvo diversos efectos: por un lado, dio lugar a la dinamización de las exportaciones favorecida por el aumento del precio de los commodities a nivel internacional. La relación exportaciones/PBI saltó del 11,6\% en 2001 al 28,4\% en $2002^{2}$, según la serie presentada por el Banco Mundial (2017), promediando el 23,7\% durante el gobierno de Néstor Kirchner (NK) (2003-2007). Además, esta dinámica en materia de comercio exterior junto al gravamen de las exportaciones a través del establecimiento de retenciones permitió captar parte de la renta y fortalecer las cuentas fiscales, dando origen a los dos pilares de estabilidad del modelo: el superávit fiscal y el superávit comercial.

A su vez, la nueva política cambiaria de "dólar caro" incrementó el precio de los productos tanto exportables como importados, generando, por un lado, un fuerte proceso inflacionario pero, por otro, formando un "paraguas" de protección a la producción local. Así, como segundo factor clave, uno de los motores principales de esa recuperación fue la industria, que se expandió entre 2003 y 2007 al 10,3\% interanual, incluso por encima del PBI en su conjunto, cuyos valores evolucionaron al 8,8\% promedio anual en el mismo período (CEP, 2008). En la década 2003-2013 se amplió la cantidad de parques industriales de 80 a 315, conllevando un aumento del $277 \%$ en las empresas industriales involucradas y del $241 \%$ de los trabajadores industriales, según datos del Ministerio de Industria.

En tercer lugar, esto llevó, por un lado, a un excelente desempeño de los grandes grupos productivos, principalmente a aquellos ligados a las exportaciones que aprovecharon el contexto nacional e internacional. Pero, por otro, también se observó una importante recomposición de las PyMEs tanto a nivel global, llegando a la creación de 229.000 unidades productivas entre 2003 y 2014, como en particular en la industria, con 17.000 nuevas empresas, según el Ministerio de Industria, con un rol fundamental en la recuperación del empleo. 
En cuarto lugar, se desplegó una política de regulación de las tarifas de servicios públicos, dando origen a un esquema de precios relativos favorable a los sectores populares y productivos. Esta política incluyó el fin del proceso privatizador y la reestatización de algunas empresas tanto en el sector de correos, como en aguas y saneamientos, trenes, aerolíneas, entre otras.

En quinto lugar, observamos una pérdida de centralidad de las estrategias de valorización financiera, con avances en la regulación del movimiento de los flujos de capitales especulativos y de la tasa de interés (con tendencia a ser negativa en términos reales), así como una mayor gravitación de los conglomerados financieros públicos. Este proceso llegó a su esplendor con hitos como la reestatización de las AFJP en 2008 y la reforma de la Carta Orgánica del BCRA en 2012. En este camino, jugaron un rol clave los canjes para salir del default de la deuda, llevados a cabo primero en 2005 , con una quita del $43,4 \%$ sobre el valor nominal inicial, que amplió plazos de amortización y reestructuró la deuda en un proceso en el que disminuyó notablemente la relación de la deuda respecto de todos los indicadores económicos y en la cual bajó la proporción de deuda externa y en divisas. En 2010 se realizó un nuevo canje con criterios similares al primero. Así, la deuda pública dejó de estar al servicio de la "bicicleta" financiera y se ampliaron los márgenes de autonomía relativa del Estado, en tanto se dio de baja el tratado con el FMI, pagando por adelantado la deuda con dicho organismo a principios de 2006. Esto sucedió pocos meses después de que Argentina, junto a otros países latinoamericanos, rechazó el plan de libre comercio continental, ALCA, propuesto por EE.UU., generando un punto de inflexión en las relaciones de fuerzas internacionales.

Esto nos lleva a un sexto factor de importancia. Se expresaron cambios en las relaciones de fuerzas sociales en el interior del bloque de poder, favoreciendo a la fracción productivo-exportadora del capital, cuyos agentes comenzaron a avanzar al interior de la cúpula empresaria, y se fue subordinando (en términos relativos) a la fracción bancaria-financiera y a la fracción del sector servicios, compuesta principalmente por las privatizadas, mientras que generó una mejora en las condiciones estructurales para las PyMEs y para las clases subalternas.

En séptimo lugar, observamos que el kirchnerismo desplegó numerosas políticas de transferencias de recursos a las clases subalternas, en materia de Salario Mínimo, con aumentos anuales por encima de la inflación, ampliación de las jubilaciones llegando casi a su universalización, multiplicación de los convenios colectivos de trabajo y potentes políticas sociales como la Asignación Universal por Hijo, el Progresar, etc.

Esto llevó a un octavo elemento: un importante descenso del desempleo, el cual pasó del 20,4\% en el primer trimestre de 2003 al 5,9\% en el último de 2015, así como de la pobreza y la indigencia, que pasaron, respectivamente, del $49,7 \%$ y el $22,8 \%$ en 2003 al $19,7 \%$ y al $4,4 \%$ en $2015 .^{3}$

En noveno lugar, se destacó una fuerte inversión estatal tanto en obra pública a través de planes de vivienda, infraestructura y energía, como en las nuevas empresas recuperadas por el Estado. En términos globales, la inversión pública tuvo un primer momento de fuerte expansión entre 2003 y 2007, del 539\%, creciendo a 
un mayor ritmo que la inversión privada en el interior de la IBIF y teniendo como novedad la inversión en las empresas reestatizadas. Un segundo momento destacado fue el rol que cumplió el Plan Obras para Todos los Argentinos, en el primer gobierno de Cristina Fernández de Kirchner (CFK), como componente clave del exitoso plan diseñado para combatir los impactos de la crisis mundial en nuestro país ${ }^{4}$.Este Programa involucró unos 114.000 millones de pesos entre 2009 y 2011, sólo por detrás de la cuadruplicación del Programa RePro que cubría parte de los salarios de empresas en crisis para sostener el empleo, y estuvo acompañado por una amplia batería de políticas orientada a la regulación del comercio exterior, el incremento de la recaudación y diversas políticas sociales y de ingresos orientadas a sostener la demanda e impulsar la inversión y el consumo para revertir el contexto recesivo que amenazaba con implantarse (Varesi, 2011).

Llegamos así al décimo factor. Se evidencian distintos elementos que marcan un aumento de la autonomía relativa del Estado, ganando mayores márgenes de posibilidad de generar e implementar políticas e intervenir en el régimen de acumulación, tanto a nivel de las variables económicas como de las fracciones de clase.

A partir de estos diez factores, entendemos que el régimen neo-desarrollista comenzó a cobrar forma en Argentina desde la puesta en marcha de un modelo productivo-exportador dado que aparecieron un conjunto de especificidades, tanto a nivel de las políticas, como de las variables económicas y las fracciones de clase, que interactuaron de modo coherente durante varios años. Su carácter productivo se basa en el destacado desempeño de la producción de bienes, y la subordinación del sector servicios y el sector financiero, factor que se vinculó al cambio de las relaciones de fuerzas sociales en el interior del propio bloque de poder. La industria volvió a recuperar un lugar y una función central en la estructura económica. Mientras que su carácter exportador, se destaca no sólo por la relación entre exportaciones y PBI, que tendió a duplicar la de los años 90, sino porque en la configuración del modelo 2002-2007 las exportaciones fueron el único componente de la demanda agregada cuyo desempeño en relación al PBI contrastó con los del modelo anterior (tomando 1993-2001), exhibiendo un incremento de 4 puntos porcentuales, mientras que la IBIF, retrocedía un $-0,6 \%$, el consumo privado lo hacía en $-3,3$ y el consumo público en $-0,3$ puntos porcentuales. ${ }^{5}$

\subsection{Kirchnerismo: relaciones de fuerzas políticas e internacionales en la estrategia hegemónica}

Ahora bien, en materia de relaciones de fuerzas políticas, el kirchnerismo dio pasos acelerados para constituir su propia fuerza hegemónica. En su origen, partió de una doble debilidad, en tanto NK llegó en 2003 al poder con sólo un 22\% de los votos y bajo el tutelaje del saliente presidente Duhalde, quien le legó, además, buena parte de su gabinete.

El Frente para la Victoria se constituyó en el espacio político a partir del cual el kirchnerismo desplegó tres tácticas políticas. La primera de ellas fue la transversalidad, la cual implicó ampliar el marco de alianzas a fuerzas políticas y organizaciones sociales "hacia la izquierda", articulando las demandas emergentes de 
la crisis de 2001. En segundo lugar, el kirchnerismo fue agrupando fuerzas para la conquista de su propio partido, el PJ, desplazando al duhaldismo con el triunfo legislativo de CFK por el senado de la Provincia de Buenos Aires en 2005 y NK llegando a la presidencia del partido en 2007. En tercer lugar, se trazó la táctica de la concertación que apuntó a sumar apoyos de otras fuerzas tradicionales como la UCR y el PS, derivando en la fórmula presidencial CFK-Cobos que se impuso en octubre de 2007.

Sobre la estrategia hegemónica global cabe una doble lectura que a su vez expresó una doble lógica del populismo: a) como lógica política, se gestó una articulación de demandas al tiempo que se conformaba un otro-poder, delimitando a su adversario en torno al neoliberalismo, en un proceso de construcción identitaria de sujeto político cuyo centro de acción partía desde el Estado mismo, presentado como emanación de la voluntad popular para reparar al propio pueblo dañado, y b) como pacto populista, promovía una nueva alianza estratégica entre trabajadores y agentes del capital productivo que pudieran encarnar el rol de la "burguesía nacional", dirigida desde el propio Estado, desplegando un sistema de transferencia de recursos para armonizar los compromisos inestables entre las fracciones de clase (Varesi, 2014).

Es por esto que entendemos que el kirchnerismo expresa una construcción ambivalente: aparecía como un proyecto de normalización política y económica suturando la crisis de 2001 de modo progresivo, que iba cobrando forma conflictivamente articulando un discurso que constituía sus propios antagonistas, ligados a los años neoliberales, y abría juego a componentes rupturistas. El kirchnerismo, sin procurar una transformación clasista del orden (en tanto las banderas del socialismo nacional eran minoritarias en su interior), avanzó a reconstituir las condiciones de empleo e ingresos de las clases subalternas en el marco de un proyecto de "crecimiento con inclusión social" basado en una suerte de "capitalismo serio o nacional". Contenía, asimismo, un elemento "herético", que proliferaba en tanto la dimensión del conflicto aparecía presente en el modo en que eran desplegadas las políticas, con la recuperación del espacio público como ámbito de disputa desde la acción estatal, la reivindicación de la militancia como herramienta de cambio, y en el ser parte de los gobiernos de América latina que comenzaron, con distintos grados de profundidad, a enfrentar el régimen neoliberal generando un proceso de cambio en las relaciones de fuerzas internacionales que dio lugar al proceso de integración regional más intenso desde las gestas independentistas, limitando la injerencia de EE.UU. y los organismos financieros internacionales. Así, el kirchnerismo comenzó a sintetizar elementos del peronismo clásico, de la juventud de los años 70, del progresismo democrático de los 80 (con una potente política de DD.HH.) sumado a la impronta latinoamericanista.

Tanto el modelo de acumulación como la estrategia hegemónica atravesaron una primera coyuntura crítica durante los años 2008 y 2009. El conflicto agrario de 2008 suscitado a partir de la Resolución 125 que establecía un sistema de retenciones móviles a cereales y oleaginosas, en un contexto de fuerte crecimiento del precio internacional de la soja, marcó un punto de inflexión. Este conflicto 
originado en un nivel económico-corporativo, debatiendo una modificación tributaria, rápidamente se convirtió en un genuino antagonismo que comenzó a poner en cuestión pilares fundamentales del modelo de acumulación y de la construcción hegemónica que lo sustentaba. En un camino trazado por la polarización, con serios errores que partían de las debilidades de la formulación original de la 125 y la subestimación del adversario, cobró forma uno de los conflictos agrarios más largo e intenso de la historia nacional, que asestó la primera derrota al kirchnerismo (Varesi, 2014b). El gobierno de CFK se vio asediado en las calles ante la potencia movilizadora de los actores del polo agrario, cayó en el Parlamento cuando buscó convertir la 125 en ley y luego en las urnas cuando, en 2009, NK fue superado por un dirigente opositor de escasa trayectoria. Más relevante aún fue que comenzó a constituirse un alineamiento opositor, desde las propias clases dominantes conformado por las patronales agrarias, los partidos opositores, los grandes multimedios y otros agentes del capital concentrado que empezaron a defeccionar del pacto social.

Aun así, el gobierno de CFK lograría dar lugar a una exitosa estrategia de recomposición hegemónica a partir de lo que denominamos como un proceso de radicalización progresista, recostándose crecientemente en los sectores según se profundizaban las políticas sociales y de ingresos, habilitando nuevos derechos civiles como el matrimonio igualitario y la Ley de Identidad de Género, buscando desmonopolizar la comunicación con una nueva Ley de Medios, con avances sustanciales en la inversión en educación, ciencia y técnica, e incrementando la gravitación del Estado con mayores capacidades de regulación e intervención económica, con importantes re-estatizaciones y una creciente articulación con los gobiernos populares de América latina, materializada en distintos procesos de integración regional (Varesi, 2011).

\section{Tensiones en el régimen neo-desarrollista: desequilibrios macro- económicos y dependencia}

Para el análisis de las tensiones que atravesaron al neo-desarrollismo argentino nos proponemos abordar diversos conjuntos de hipótesis convergentes. El primero es producto del propio proceso de investigación y se materializó inicialmente en las conclusiones de mi tesis de doctorado (Varesi, 2013), redactadas entre 2011 y $2012^{6}$, y desarrolladas en base al estudio detallado de las dinámicas de hegemonía y acumulación entre 2002 y 2008. En ellas se delimitaron las principales tensiones en ambas dimensiones realizando un ejercicio predictivo el cual quedó plasmado en su mismo título: "Neo-desarrollismo, populismo y sujetos. Entre la profundización rupturista y la restauración neoliberal". Muy sintéticamente, se identificaban un conjunto de continuidades del régimen neoliberal que pervivían en el neo-desarrollismo y se planteaba que las mismas incidían en sostener un conjunto de rasgos estructurales y un esquema de relaciones de fuerzas sociales favorables a distintas fracciones del gran capital que entraban en contradicción con otros componentes del modelo y la estrategia de construcción de hegemonía. Principalmente, el alto nivel de concentración y extranjerización, junto al manteni- 
miento de una similar matriz productiva, comenzaban a tensionar la ampliación de la autonomía relativa del Estado, otorgándole a la cúpula económica una potente capacidad de veto, manteniendo un poderío estructural con posibilidad de formar precios, manejar divisas y poner límites a las estrategias distributivas. A su vez, como plantearemos más adelante, se generaban hipótesis sobre las contradicciones emergentes entre los rasgos y estrategias de las principales fracciones de clase, según el lugar y función ocupados en la estructura, y la estrategia de hegemónica imperante, reposicionando la mítica pregunta por la igualmente mítica "burguesía nacional", el rol del Estado y la relación con las clases subalternas.

Pero antes de avanzar en esa línea y contrastarla con la nueva evidencia surgida de la ampliación del período de estudio, es importante recuperar otra línea de análisis de tensiones que, siendo posterior, se muestra convergente y enriquecedora: la propuesta de Schunk et al. (2014). Ésta también nos permite indagar la relación entre las bases estructurales de la hegemonía y el funcionamiento concreto de los modelos de acumulación en un país periférico. Los autores sostienen que "Los gobiernos de matriz popular (o populista), deben su legitimidad política a la implementación de lo que podemos llamar un "modelo económico distributivo" asentado sobre la promoción del consumo popular, las mejoras en el empleo, en los ingresos del trabajo y en el gasto público social" (Schunk et al., 2014: 7). Su hipótesis central es que el desarrollo de este tipo de modelo en un país periférico tiende a generar un conjunto de obstáculos estructurales que, si no son resueltos, limitan su capacidad de sostenerse en el largo plazo en tanto "provocan una acumulación de desequilibrios macroeconómicos que finalmente obstruyen la senda de la expansión con equidad" (2014: 8).

Ambas líneas de investigación confluyen, ya que si entendemos que el régimen de acumulación neoliberal tuvo como consecuencia afianzar el carácter periférico y dependiente de la estructura económica nacional, entonces los factores de continuidad del mismo durante el régimen neo-desarrollista constituyeron el sustrato material de los obstáculos y consecuentes desequilibrios.

\subsection{Factores de crisis y contradicciones en el régimen neo-desarrollista}

Ahora bien, ¿qué continuidades marcaron críticamente el desempeño del régimen neo-desarrollista? ¿cuáles son los principales obstáculos estructurales que empezaron a materializarse en desequilibrios macroeconómicos?

En primer lugar, la elevada extranjerización económica. Los datos de la Encuesta Nacional a Grandes Empresas (ENGE) muestran que, por un lado, en el período 2012-2015 hubo un descenso en el nivel de extranjerización de las primeras 500 empresas, en tanto las empresas con participación de capital extranjero pasaron de explicar el 78,4\% del Valor Bruto de Producción del panel al 74,5\% (INDEC, 2017). Sin embargo, una mirada a la serie histórica permite observar que no se llega a revertir el proceso dejado por el neoliberalismo, sino que queda por encima del 72,5\% que las empresas extranjeras tenían en 1997.

La extranjerización implica la derivación de excedentes a sus casas matrices en el exterior a partir de tres factores: la remisión de utilidades, el endeudamiento con 
las casas matrices o empresas del mismo grupo y el pago de regalías y honorarios profesionales. Como expresan Schorr y Wainer, "la remisión de utilidades pasó de significar el $21,7 \%$ de las entradas de IED durante la convertibilidad (promedios anuales) al 48,8\% durante el kirchnerismo" (2017: 162). Estos mismos autores presentan, a su vez, evidencia de cómo se amplió la deuda comercial de las filiales con sus casas matrices o empresas del grupo, pasando de representar el 30,7\% del stock de deuda externa privada en 2002 al 44,2\% en 2015, mientras que las remesas en concepto de regalías y honorarios profesionales saltaron de 960 millones a 4.973 millones de dólares, en el mismo período.

El segundo factor a destacar es que en este camino de externalización también confluyen buena parte de los excedentes conseguidos por el gran capital local, cuya reticencia inversora y prácticas rentísticas, tienden a convertirlos en fuga de capitales. Según Schunk et al. (2014) los datos de fuerte concentración presentes en la economía no conllevan a un creciente desempeño inversor sino todo lo contrario, una tendencia a la baja reinversión y escasa apuesta al desarrollo en I+D. Por su parte, el estudio de Manzanelli (2015) nos permite ver este contraste entre concentración e inversión o, lo que es igual, la correlación observable entre concentración y reticencia inversora, en tanto sostiene que: "La tasa de inversión bruta en el selecto panel de las grandes empresas descendió del $29,2 \%$ en el período 1993-2001 al 16,8\% en la posconvertibilidad (2002-2011), situación que contrasta con la dinámica nacional, según la cual (...) la tasa de inversión total ascendió del $18,1 \%$ al $21,6 \%$ y la privada del $16,7 \%$ al $18,4 \%$, respectivamente" (2015: 88). El mismo Varesi concluye que los capitales no reinvertidos se fugan al exterior, indicando que "las ganancias no reinvertidas por esta cúpula empresaria contabilizaron 71.688 millones de dólares, mientras que la salida de capitales al exterior alcanzaron a 87.108 millones entre 2008 y 2011" (Manzanelli, 2015: 95). La fuga de capitales se convierte así en otra de las vías de demanda de divisas que incide en el deterioro de las cuentas externas nacionales.

En tercer lugar, cabe mencionar que para intentar contener este drenaje de divisas, durante el segundo gobierno de CFK se agudizaron los controles cambiarios dando origen al denominado "cepo". Esta política que estableció distintas restricciones a la compra de divisas que, si por un lado, logró disminuir la fuga de capitales entre 2012 y 2014, por otro lado, como señalan Porta et al. (2017), además de ser impopular en los sectores medios generó una ampliación de la brecha entre el dólar oficial y el paralelo que promedió el $60 \%$ en 2013, incentivando el turismo al exterior lo cual agravó la pérdida de divisas con una balanza deficitaria de 6.600 millones de dólares en el sector, y además comenzó a afectar el funcionamiento de la actividad económica y creó un clima favorable a la especulación financiera.

Un cuarto elemento se encuentra ligado a la matriz productiva, cuya continuidad en el perfil estructural impidió revertir su carácter desarticulado y dependiente, requiriendo grandes cantidades de insumos y maquinaria importada para seguir su expansión, conllevando otra vía de fuerte demanda de divisas. Como plantean Schorr y Wainer (2017), la industria volvió a presentar una balanza comercial deficitaria a partir de 2007 debido a diversos factores tales como 
lo acotado del proceso de sustitución de importaciones en ausencia de un plan de reindustrialización consistente, la histórica dependencia tecnológica y el afianzamiento de la dualidad estructural del sector fabril, en el cual un puñado de empresas ligadas al procesamiento de recursos básicos presenta un saldo positivo mientras que el resto del entramado sigue mostrando déficit. Esto se liga, a su vez, con el dinamismo de industrias que son fuertemente demandantes de divisas en virtud del alto componente de insumos importados, como la automotriz o el polo de ensamble electrónico de Tierra del Fuego cuyos balances comerciales en 2013 resultaron deficitarios en 5.986 millones y 4.000 millones de dólares, respectivamente (CIFRA, 2015b).

Un quinto factor, de destacado impacto sobre la balanza de pagos, es la crisis energética. El crecimiento de largo plazo del régimen neo-desarrollista no fue acompañado por igual desempeño de la producción de energía, cuyo sector continuó con las prácticas predatorias características de los años 90, con alta explotación y baja exploración. Según datos del Ministerio de Energía, la oferta energética primaria argentina es explicada en un $85,7 \%$ por la producción hidrocarburífera (año 2015), la cual parte de un sector fuertemente oligopolizado y, hasta hace no muchos años, altamente extranjerizado. Este sector tuvo como exponente las prácticas de Repsol, empresa que, a partir de la privatización de YPF, financió con la extracción de los recursos energéticos argentinos su estrategia de expansión a escala mundial generando un genuino "saqueo". ${ }^{7}$ Según plantea Krakowiak (2016), entre 1993 y 1998 -último período estatal- el promedio de pozos explorados por YPF fue de 77 por año, mientras que a cargo de Repsol, este promedio se redujo, entre 1999 y 2004, a 26 por año, un $70 \%$ menos, y peor aún entre 2005 y 2010 , descendiendo a sólo 13 pozos por año, un 84\% menos. Esto llevó a que entre 1999 y 2011 las reservas de petróleo de YPF disminuyeran de 123 a 63 millones de metros cúbicos, un 49,8\%, y las de gas de 191 a 50 millones de metros cúbicos, un 73,8\% (Barrera, citado por Krakowiak, 2016). Este accionar motivó, en 2012, la estatización del 51\% de YPF, cuyos indicadores mejoraron desde aquel momento pero sin el tiempo suficiente como para revertir el cuadro dramático de la crisis energética, con exportaciones a la baja y la necesidad de importar energía con los altísimos costos que eso conlleva. Ya desde 2011 la balanza energética había comenzado a ser deficitaria y desde ese año hasta 2015 inclusive drenó unos 22.340 millones, equivalente a 4.468 millones de dólares en promedio anual.

A partir de estos cinco factores mencionados se restableció un problema histórico de la estructura económica argentina, el cual marca su carácter dependiente: la restricción externa, es decir, la falta de divisas que comenzó a evidenciarse en la caída de las reservas internacionales, las cuales tras haber alcanzado su pico de 46.376 millones de dólares en 2011 cayeron año tras año hasta alcanzar los 25.563 millones de dólares en 2015. En este contexto, aparecían dos vías principales para hacer frente, al menos circunstancialmente, a los desequilibrios: sostener el pilar del superávit comercial para garantizar el flujo constante de divisas y/o tomar deuda a modo de "parche" mientras se buscaba solución a los problemas estructurales previamente señalados. 
Con respecto a la primera opción, el segundo gobierno de CFK vio deteriorarse el saldo de la balanza comercial, el cual pasó de un superávit de 12.008 millones de dólares en 2012 a llegar al primer año deficitario del todo el régimen neo-desarrollista en 2015 con saldo de -3.035 millones de dólares. Por su parte, tras realizar un nuevo exitoso canje de deuda en 2010 y concretar las negociaciones para pagar la deuda con el Club de París en 2014, el retorno a los mercados financieros internacionales recibió finalmente un serio revés a partir del fallo del juez Griesa de Nueva York a favor de los "fondos buitres", el 7,3\% que había rechazado los canjes que sacaron a la Argentina del default en 2005 y la segunda chance de 2010 y que buscaba cobrar muy por encima de lo pautado con el 92,7\% de los acreedores. El conflicto llevó a lo que las calificadoras de riesgo entendieron como un default técnico, obstruyendo la estrategia oficial para volver a acceder a los mercados internacionales de créditos a tasas razonables.

Volviendo a la identificación de los distintos factores estructurales que llevaron a crisis al régimen neo-desarrollista, debemos señalar que en un contexto de restricción externa se hace aún más notorio el poderío de quienes controlan las divisas. En nuestro país, las divisas se encuentran concentradas en los reducidos núcleos del gran capital que controlan la exportación, cuyas acciones repercuten decisivamente sobre las variables económicas. Hacia el año 2015, sólo 50 empresas explicaban el $64 \%$ del valor total exportado. ${ }^{8}$ Esta concentración era aún mayor en el agro donde unas 10 empresas exportaron, en dicho año, el $63 \%$ de los granos. ${ }^{9}$ Esta favorable correlación de fuerzas sociales y su capacidad de incidir sobre el funcionamiento de la economía queda de manifiesto cuando observamos que el sector agro-exportador venía generando un fuerte acopio de cosecha de unos 11.400 millones de dólares. Esta capacidad de retener exportaciones aportó a "secar" la economía local de dólares, incrementando la restricción externa, buscando forzar una devaluación.

Así, el poder estructural de la gran burguesía local continuó casi intacto en base a su creciente concentración. En base al análisis de los datos de la ENGE, el Valor Bruto de Producción de las principales 500 empresas, si bien presenta un proceso de desconcentración entre 2012 y 2015 , pasando de expresar del $26,2 \%$ al $24,3 \%$ del VBP del total de la economía (INDEC, 2017), estos valores se ubican muy por encima de los años del régimen neoliberal, los cuales en 2001 eran del 16,6\%. Estos indicadores nos hablan de que las relaciones de fuerzas sociales siguieron siendo ampliamente favorables al gran capital, aumentando su capacidad de incidencia sobre las variables económicas así como su capacidad de veto sobre las políticas públicas. ${ }^{10}$

Estos datos se ratifican, asimismo, cuando se indaga acerca de las 200 principales empresas, la "cúpula empresaria" que, como señalan Castellani y Gaggero (2017), incrementó su participación sobre el PBI, pasando del 15,7\% en 2001 al $20 \%$ en 2014, explicada principalmente por el desempeño de las primeras 50 empresas.

Este poder concentrador también incidió en otro factor de desestabilización del neo-desarrollismo: la inflación. Si bien en los orígenes del modelo productivo- 
exportador la inflación fue principalmente de origen cambiario, a partir de 2007, cuando la recomposición salarial comenzó a ser vista por el bloque de poder como una amenaza a la ganancia empresaria, ésta se explicó por las dificultades para arbitrar la puja distributiva. La existencia de grandes formadores de precios en la producción y grandes comercializadores (como los hipermercados que concentran las ventas en el mercado interno) derivaron en el traspaso de los aumentos salariales a precios, estimulando el proceso inflacionario y, asimismo, limitando la capacidad de la acción estatal para sostener las transferencias de recursos hacia las clases subalternas vía mejoras de la distribución funcional. Ésta, a pesar de las resistencias del gran capital siguió mejorando y la participación de los asalariados en el PBI se expandió incesantemente con el kirchnerismo desde el 33,46\% en 2003 al 48,2\% en $2015^{11}$, su mejor año.

Aquí vemos una de las contradicciones claves del régimen neo-desarrollista, su esfuerzo distributivo tendía a chocar inevitablemente con la continuidad de la concentración económica y el fortalecimiento de los grupos más poderosos del gran capital. Ahora bien, debe tenerse en cuenta que las limitaciones a la distribución impuestas por el bloque de poder buscaron ser compensadas por el gobierno con mayor inversión estatal en diversas áreas sociales y en transferencias directas e indirectas a las clases subalternas, afrontadas con recursos públicos. También debe señalarse, como plantean Castellani y Gaggero (2017) que las erogaciones destinadas al capital también se incrementaron a través de la expansión del gasto público en servicios económicos, el cual se sextuplicó entre 2002 y 2013, abarcando algunos ámbitos privilegiados de acumulación favorable a los grupos económicos locales como en los grandes planes de obra pública, servicios públicos, juegos de azar, construcción, energía, transporte, etc.

Aquí se abre otro frente de crisis en el neo-desarrollismo argentino: la recaudación no acompañó el aumento del gasto público, el cual además, en el contexto de la crisis mundial se expandió como parte de la estrategia que buscaba la reactivación económica. Así, se comenzaron a erosionar las cuentas fiscales llevándolas a déficit, aspecto que implicó el deterioro de uno de los pilares de sustentabilidad del modelo. En este contexto, el resultado fiscal primario entró en déficit en 2012, de $-0,16 \%$ en relación al PBI, siguiendo un camino de deterioro hasta el $-1,73 \%$ en $2015 .^{12}$

De este modo, observamos cómo los desequilibrios macroeconómicos están vinculados en su raíz a las continuidades prevalecientes desde el régimen neoliberal. Esto refiere a que fue la propia insuficiencia de transformaciones estructurales del régimen neo-desarrollista lo que sostuvo un cuadro estructural de relaciones de fuerzas sociales que habilitaron la contra-ofensiva restauradora. A su vez, la persistencia de los diversos factores propios de una economía dependiente impidió remover los obstáculos para generar un desarrollo sostenido con inclusión social.

\subsection{Interrogantes e hipótesis}

A partir de caracterizar los factores de crisis y contradicciones observables se nos abre una nueva pregunta, ¿los desequilibrios estructurales acumulados nos ha- 
blan de un colapso del régimen neo-desarrollista? Entendemos que no, si bien los problemas eran varios y con distintos grados de seriedad, la clave de lectura a la que nos lleva nuestro enfoque contrastado con la evidencia empírica nos señala la siguiente hipótesis: lo que estaba en crisis era, particularmente, un primer modelo del neo-desarrollismo argentino, el modelo productivo-exportador. Asimismo, entendemos que hubo intentos desde el Estado de cambiar algunos de los elementos en crisis pero que no alcanzaron resultados que permitieran establecer un nuevo modelo.

El modelo productivo-exportador comenzó a mostrar signos de deterioro a partir del cambio de escenario internacional, signado por la crisis mundial, con contracción del comercio exterior y, particularmente, caída de los precios de los commodities.

Un primer indicador que permite sustentar esta hipótesis es la reducción constante que presentaron las exportaciones tras alcanzar un pico de 82.981 millones de dólares en 2011, todos los años del segundo gobierno de CFK exhibieron caídas, hasta llegar a su punto más bajo en 2015 , de 56.752 millones de dólares. ${ }^{13}$

Esto también se observa en la variación de la relación de las exportaciones sobre el PBI. Dicha relación que, como vimos, superó su duplicación comparando el promedio anual de 2003-2007 y el año 2001, exhibía la realización del capital vía exportaciones como una de las claves centrales del modelo y, a su vez, incidió en forjar uno de sus pilares de sustentabilidad: el superávit comercial, cuyo desempeño gravado por retenciones, colaboró con la consecución de muchos años de superávit fiscal. Durante el primer gobierno de CFK (2008-2011) esta relación, si bien menor, promedió el 19,8\%, todavía muy por encima de los años 90 . Es durante el segundo gobierno de CFK cuando comenzamos a ver un declive pronunciado de la relación exportaciones/PBI, la cual termina en un 11\% en 2015, por debajo de los valores de 2001, y dando origen al primer año de déficit comercial del modelo.

La crisis del modelo productivo-exportador se encuentra también corroborada en que "el componente de la demanda que registró sistemáticas caídas interanuales fueron las exportaciones" (CIFRA, 2016: 3), lo cual se evidencia en que su tasa anual acumulativa cayó un $-4,6 \%$ entre 2012 y $2015^{14}$, en un contexto de caída de precios y compras externas por parte de los principales socios comerciales tanto de Argentina como Brasil, China y la Unión Europea, mientras que la inversión se estancó, mostrando un crecimiento de sólo el 0,4\% en el mismo período. Por el contrario, el componente más dinámico de la demanda fue el Consumo Público, con un aumento del 4,5\% como parte de las políticas anti-cíclicas que buscaron estimular el crecimiento y apuntalar los ingresos de los sectores más vulnerables de la sociedad.

La evolución de la industria también marcaba un área llena de complejidades. Tras un notable desempeño durante el gobierno de NK y una importante recuperación en los dos últimos años del primer gobierno de CFK, superando los primeros embates de la crisis capitalista internacional, en el segundo gobierno de CFK la industria tuvo un magro resultado. El año 2012 mostró una variación interanual 
negativa, del $-2,97 \%$, seguido por una evolución positiva del 1,6\% en 2013, otro año contractivo en 2014 del $-5,10 \%$ y una leve recuperación del $0,24 \%$ en $2015 .{ }^{15}$

En este contexto, la industria que había sido un estandarte del modelo productivo-exportador alcanzando a explicar en términos de su valor agregado, durante su período de configuración 2002-2007, el 33,6\% del PBI en promedio, y un 30,4\% promedio durante el primer gobierno de CFK (2008-2011), terminó en 2015 en el $28 \%$, sólo un punto porcentual por encima del año $2001 .{ }^{16}$

Esta crisis del modelo productivo-exportador derivó en un proceso de desaceleración económica global evidenciada en una tasa de crecimiento acumulativa anual del PBI entre 2012 y 2015 de sólo el 1,8\%, que en término del PBI per cápita fue del $0,7 \% .^{17}$

A pesar de la entrada en crisis de múltiples variables económicas, el gobierno intervino a través de variadas iniciativas como Procrear, Procreauto, Ahora 12, Proemplear, RePro, Progresar, aumentos de la AUH, salario mínimo, jubilaciones, etc. tanto con el fin de generar medidas anti-cíclicas para sostener la demanda a través del consumo y el empleo, como de mejorar la distribución con orientación al mercado interno, permitiendo vislumbrar acciones orientadas a virar del inicial modelo productivo exportador hacia uno que terminara de materializar en la economía el proyecto nacional-popular que se esbozaba en el plano de la política.

\section{Estructura social, estrategia hegemónica global y aspectos coyunturales}

Hay otro conjunto de elementos de análisis de la estructura social que convergieron en incrementar las tensiones en el interior del régimen de acumulación y que se ligan con la estrategia de construcción hegemónica desplegada por el kirchnerismo.

Si entendemos que el bloque histórico expresa la relación dialéctica entre las superestructuras y la estructura, entonces es pertinente indagar la correspondencia y las contradicciones que emergen del movimiento concreto de los planos de la hegemonía y del proceso de acumulación. Ahora bien, el devenir hegemónico de una fuerza político-social implica la universalización del proyecto que encarna, lo cual, en el caso del kirchnerismo implica dar cuenta de la estrategia del pacto populista y el proyecto de "crecimiento con inclusión social", el cual, como dijimos, parte de una matriz ideológica nacional y popular con otros aditamentos ligados a la juventud de los años 70, factores del progresismo democrático y sobredeterminado "a la izquierda" por el proceso de integración latinoamericano. La sustentabilidad de toda experiencia que procura regir el bloque histórico precisa de cierto grado de correspondencia entre sus elementos y pone en juego su capacidad para sortear y superar las contradicciones o al menos mitigar sus efectos. Entramos aquí en el segundo conjunto de lecturas e hipótesis proveniente de la investigación de largo plazo (Varesi 2011; 2013; 2014; 2016b).

En relación al pacto populista, se hacen manifiestas algunas contradicciones entre la estrategia político-hegemónica y los sujetos evocados en la misma. El Estado es pensado como orientador de una articulación poli-clasista que busca 
organizar los "equilibrios inestables" tanto en el interior del bloque en el poder como entre fracciones de éste y las clases subalternas. Ya en la experiencia reciente como pasada, la estrategia de pacto social no sólo precisa de un Estado fuerte que amplía su autonomía relativa para poder ejercer esta capacidad de conducción, sino también de ciertos rasgos y compromisos de los sujetos interpelados en la estructura de clases.

Se hace presente aquí, una vez más, la pregunta ya mítica por la "burguesía nacional", es decir por una fracción productiva y local de la clase dominante que pueda comprometerse con un proyecto de desarrollo soberano y que acepte otorgar concesiones hacia las clases subalternas para poder materializar el pacto, al tiempo que oriente sus prácticas empresarias a sustentar dicho desarrollo, lo cual implica un proceso de inversión, ampliación de las capacidades técnicas y tecnológicas así como la remoción de aspectos claves que hacen a la dependencia de una nación que ocupa un lugar periférico en el orden mundial. Si bien ésta es una tarea de universalización de la concepción de mundo eminentemente política e ideológica, debe tener anclaje estructural, ya que precisa encontrar en las clases, fracciones y agentes concretos que puedan converger y materializar esa propuesta hegemónica.

Pero es en el análisis de la estructura social, especialmente de las clases dominantes y en particular del capital productivo, donde emerge una primera contradicción.

Por un lado, encontramos una fracción del capital productivo-exportador, la cual se puso a la cabeza del bloque de poder desde la emergencia del régimen neo-desarrollista en virtud de los cambios en las relaciones de fuerzas sociales, las características del funcionamiento de las variables económicas y las políticas económicas que nos llevaron a visualizar un modelo con especificidades propias que nominamos como productivo-exportador.

Sin embargo, los propios rasgos de esta fracción dominante parecían dificultar una complementación de intereses: tanto su concentración y extranjerización, como su lógica exportadora, hacían que lejos de ver en el salario un factor fundamental (como consumo en el mercado interno) para la realización del capital, encuentren en él un costo que buscaba ser limitado para ganar rentabilidad; ya que una de las claves de la competitividad internacional y ganancias empresarias se hallaba en la combinación entre aumento de la productividad y el inicial bajo costo laboral, sobre todo en términos de divisas.

Identificamos, a su vez, un corte en términos de productividad: las grandes empresas tendían a proveer salarios mejores que los de las PyMEs pero que no constreñían sus altos niveles de rentabilidad, los cuales estaban habilitados por el modelo y la coyuntura internacional favorable, por supuesto con variaciones a lo largo del período. Del otro lado del corte por productividad se ubicaban las PyMEs, empresas orientadas principalmente al mercado interno y que podrían verse beneficiadas por un creciente poder de compra de los agentes subalternos. Sin embargo, la baja productividad de estas empresas ponía a los bajos salarios como condición de rentabilidad y subsistencia de esta fracción, cuya posición y 
función en nuestra estructura social las hace tan importante en términos de empleo. Esta histórica desestructuración de la matriz económica permitía entender tanto su rol clave en términos cuantitativos hacia las clases subalternas, a partir de la generación de puestos de trabajo, como las magras condiciones cualitativas de esos empleos, con salarios casi a la mitad de los que proveían de las grandes empresas y con un índice de informalidad laboral que duplicaba el de aquellas, haciéndose mayor cuanto más pequeño era el establecimiento. Así, otra fracción que podría encarnar potencialmente a la "burguesía nacional", ya que incluso está mucho menos extranjerizada que el resto de las fracciones dominantes, se alejaba de las pretensiones invocadas en los discursos.

Ésta era a su vez una de las razones destacadas de los limitantes estructurales de la distribución del ingreso: por un lado, aquellos agentes que podían otorgar mayores salarios no necesitaban hacerlo para la realización de su capital y, por el contrario, su capacidad de formación de precios los habilitaba a trasladar a éstos los incrementos otorgados en materia salarial y, por otro, aquellos que se beneficiaban del mayor desarrollo del mercado interno no podían dar mejoras salariales sustanciales a causa de sus limitaciones de productividad y escala. Sin embargo, esta situación contradictoria generó un "equilibrio inestable" que logró sostenerse por un tiempo, con una tendencia a la mejora distributiva hacia las clases subalternas, donde los aumentos salariales comparativamente altos (en relación al resto de la estructura salarial) abonados por el gran capital productivo impulsaron el consumo, y la generación de empleo de las PyMEs sumado a las políticas sociales y de ingresos, sumaron también al mercado interno a sectores con una mayor propensión marginal a consumir, sectores que antes se encontraban al límite de la subsistencia y que fueron favorecidos por la recomposición de las condiciones de vida de las clases subalternas.

Pero este equilibrio inestable comenzó a crujir cuando, por un lado, la recomposición salarial comenzó a ser percibida como una amenaza a las ganancias del gran empresariado y, por otro, cuando comenzó, a partir del conflicto agrario de 2008, a configurarse un bloque político-social alternativo que proponía limitar la injerencia del Estado en la economía y re-impulsar una legitimación de las políticas de libre mercado como mejor asignador de recursos. Como vimos, este nuevo alineamiento opositor logró, en materia electoral, asestar el primer golpe con la derrota de NK en las elecciones legislativas de 2009.

Así, el pacto populista comenzó a perder potencia por la defección creciente de fracciones del bloque de poder: si la primer gran ruptura se gestó cuando la fracción agroindustrial se desligó durante el conflicto agrario, junto con las principales corporaciones multi-mediáticas, un segundo momento de deterioro tuvo lugar cuando en 2013 una fractura del FPV dirigida por Sergio Massa ${ }^{18}$ se llevó tanto a algunos dirigentes políticos del peronismo como a referentes del capital productivo como De Mendiguren, dando origen al Frente Renovador. En 2013 la candidatura de Massa a diputado de la provincia de Buenos Aires ejerció un segundo revés electoral al FPV al imponerse con un 44\% de los votos. Así, esta fuerza, se ubicó temporalmente al frente del espacio opositor, mostrando un perfil 
más moderado que otros partidos, como el PRO, de corte más netamente liberal y conservador; logró también la adhesión de parte del sindicalismo, como el sector moyanista y el que respondía a Luis Barrionuevo dentro de la CGT.

En este contexto, se evidenciaron carencias en la propia estrategia de la fuerza oficial, ya que el pacto social no sólo empezó a deteriorarse por la defección de la gran burguesía, sino que, a diferencia de otros procesos peronistas, careció de un movimiento obrero organizado como columna vertebral. Si bien el kirchnerismo logró originalmente promover la unificación de la CGT, con el pasar de los años se llegaría a un nivel de fragmentación alto en términos históricos: cinco centrales sindicales, a partir de la división de la CGT en tres y de la CTA en dos, de las cuales finalmente sólo respondían de forma más o menos orgánica una fracción de la CTA y un sector de la CGT.

Además, si por un lado hubo un avance sustancial en materia de convenios colectivos de trabajo y en el conjunto de políticas orientadas a los trabajadores, por otro, la informalidad laboral terminó en niveles similares a los de los años 90 , abarcando cerca de un tercio de los trabajadores.

Estos factores muestran las limitaciones que existieron para construir un sujeto colectivo subalterno con centralidad en la clase y el movimiento obrero. Tampoco prosperó el último armado táctico que se suponía llamado a motorizar la profundización, Unidos y Organizados. De este modo no se aspiró (o no se alcanzó), como en los procesos populares contemporáneos más radicalizados de América latina, a construir un poder alternativo basado en las organizaciones populares dando lugar a una nueva institucionalidad. Así, quedó un piso endeble tanto a nivel político como social para resistir la contra-ofensiva que venía creciendo. De hecho, frente al avance del alineamiento opositor, la propia CFK advertía en 2014, en un discurso frente a la militancia, que dicha coalición del bloque de poder venía "para acabar con todas las conquistas sociales, por eso presionan con maniobras de especulación, para licuar todo lo que se ha ganado en estos años, para licuar el poder adquisitivo de los trabajadores, para tirar abajo las convenciones colectivas de trabajo. Porque vienen por eso: por las conquistas sociales, para que haya mayor ganancia y rentabilidad a partir de que otros ganen menos" (30/9/2014). Sin embargo, sería con el triunfo de dicha coalición, que finalmente cobraría el nombre de Cambiemos a partir de la alianza entre el PRO, la UCR y la Coalición Cívica, cuando se evidenciaría lo endeble de la constitución de un sujeto colectivo organizado para resistir el avance sobre esas mismas conquistas.

Asimismo, encontramos una serie de medidas económicas que coadyuvaron a deteriorar las adhesiones de los sectores subalternos al gobierno kirchnerista. En primer lugar, la fuerte devaluación de 2014, derivada de la combinación de restricción externa y especulación contra la moneda local, generó un pico inflacionario del $36,8 \%$, el más alto hasta entonces desde la fundación del régimen neo-desarrollista, conllevando la contracción del 4,8\% del salario real de los trabajadores formales del sector privado, y un aumento de la pobreza de 2,6 puntos porcentuales, afectando a los sectores más vulnerables de la sociedad. ${ }^{19}$ En segundo lugar, la negativa del gobierno a actualizar sustantivamente el mínimo no imponible del 
impuesto a las ganancias en un contexto de alta inflación socavó apoyos en la base social del kirchnerismo. En tercer lugar, la restricción a la compra de divisas afectó a los sectores medios, tanto en el acceso al dólar como modalidad de ahorro como para la realización de viajes al exterior, aspecto que podría haberse solventado con una mayor regulación del comercio exterior donde se encuentran concentradas principalmente las divisas (Boron, 2016).

Asimismo, en el plano de la disputa hegemónica, Boron (2016) señala un conjunto de "causas inmediatas", de tipo coyuntural, que llevaron a la derrota del balotaje de 2015 y que estuvieron ligadas a distintos errores de campaña. En primer lugar, el hostigamiento a Scioli por parte de la conducción kirchnerista durante años, tanto en términos políticos como económicos, traspasando escasos recursos a la provincia, quitó posibilidades a quien luego CFK eligiera de candidato. En segundo lugar, el no haber apoyado a Lousteau en el balotaje de la Ciudad de Buenos Aires contra Larreta, impidió gestarle una derrota al PRO que hubiera sido estratégica. ${ }^{20}$ En tercer lugar, Boron señala que fue un error que CFK eligiera quien acompañaría a Scioli en la vice-presidencia, privilegiando garantizar la futura obediencia de la fórmula presidencial a ella en vez de buscar un candidato competitivo que pudiera sumarle votos. En cuarto lugar, Boron sostiene fue problemática la estrategia de proponer a Aníbal Fernández y a Martín Sabatella como candidatos en la interna provincial, ya que si bien tenían apoyos también tenían elevados índices de rechazo. Aquí se hizo presente un quinto factor, el internismo que desató luchas intestinas (el "fuego amigo") en el interior del FPV provincial y restó apoyos. La derrota de la fórmula en la provincia de Buenos Aires fue clave para el triunfo de Cambiemos a nivel nacional. Y finalmente, el estilo de campaña negativa, basada en resaltar lo pernicioso que sería un gobierno de Macri y la estrategia de sólo defender "hacia atrás" lo logrado, dificultó poder mostrar cuáles serían los lineamientos a futuro, sin tomar en cuenta, además, que las encuestas indicaban que amplios sectores de la sociedad querían algún tipo de cambio. Además, Boron añade que la conducción del FPV, sin prever la posibilidad de la derrota, buscó que Scioli ganara por un escaso margen de modo de poder tenerlo bajo su control. Aun así, llegado el escenario del balotaje, Boron rescata las masas militantes que se volcaron a las calles para evitar el retorno al neoliberalismo.

Pero debemos señalar que ni los factores estructurales de crisis ni los errores coyunturales en materia política alcanzan por sí mismos (al menos en principio) para derribar un modelo distributivo como el que desplegaba el kirchnerismo, sino que requieren de un despliegue en términos político-ideológicos, que se articula con la construcción de hegemonía por parte de los sectores más concentrados del bloque de poder. Como sostenían de forma premonitoria Schunk et al.:

"Frente a las dificultades reales, el establishment, de mucho poder en la Argentina, suele generar una operación perversa: identificar las tensiones económico-sociales con la acción "populista", demagógica y hasta "irracional" del gobierno de turno. Luego, temas sensibles a la población, como la "inflación", el "cepo cambiario", la "falta de empleo" (para ponerlo en términos actuales), e incluso cuestiones económicas importantes 
como el "déficit público" o la merma en las inversiones, son imputadas sencillamente a las políticas erróneas, caprichosas y/o animadas por la "corrupción". El debate público-mediático logra entonces responsabilizar al gobierno por los grandes problemas, pero evitando cuidadosamente ahondar en el cuadro estructural que esos fenómenos expresan. La solución que el establishment generaliza, por lo tanto, pasa por un camino muy sencillo: cambiar el gobierno. (...) Con ello se interrumpe el ciclo político de matriz popular y se propicia un retorno a la ortodoxia. Vuelven entonces las políticas orientadas por el mercado, incapaces de promover un proceso de desarrollo. De tal modo, se resigna la posibilidad de resolver los obstáculos estructurales y se abre un nuevo ciclo político caracterizado por el ajuste, la deuda externa ligada con la especulación financiera, la retirada del Estado, la desregulación y la plena liberalización comercial y de capitales" (2014: 13).

Así, las tensiones estructurales y las limitaciones de la construcción de hegemonía habilitaron un escenario en el cual la fuerza político-social que logró plantearse como la alternativa, encarnaba el proyecto restaurador favorable a las fracciones disidentes del bloque de poder con una alineación estrecha con la contraofensiva que EE.UU. venía desplegando en la región en el marco del cambio en las relaciones de fuerzas internacionales. Tensiones y límites que enfrentaron una lúcida construcción opositora y se anudaron en un desenlace definido por apenas el 51,3\% en el balotaje favorable a Cambiemos, dando inicio a un proceso de reforma estructural que en pocos meses desmontaría buena parte de lo alcanzado en el proceso anterior.

\section{Conclusiones}

En Argentina, tras la crisis de 2001 que sacudió el bloque histórico a nivel nacional, se conformó un modelo productivo-exportador que constituyó la primera experiencia del régimen neo-desarrollista. En su configuración, el despliegue industrial junto con su impronta exportadora, ayudada por el favorable contexto de precios internacionales, constituyeron dos ejes cardinales habilitados por un amplio espectro de políticas que dieron fin al modelo de la convertibilidad, como momento más acabado del neoliberalismo local. La política de tipo de cambio competitivo, las retenciones a las exportaciones, la regulación de tarifas, de la tasa de interés y del movimiento de los flujos de capital financiero, junto con la llamada política de "desendeudamiento" y la creciente inversión pública, forjaron un esquema macroeconómico que se sustentó en base a dos pilares: el superávit fiscal y el superávit comercial. El Estado ampliaba su autonomía relativa, tanto en materia de intervención y regulación como también a partir de distintas estatizaciones de empresas y se legitimaba con la recuperación del empleo y la mejora de todos los indicadores sociales, bajando sustancialmente la pobreza y la indigencia, a partir de una amplia batería de políticas sociales y de ingreso tanto en materia de salario mínimo, jubilaciones como convenios colectivos de trabajo. Este proceso se vinculaba directa- 
mente con los cambios en las relaciones de fuerzas sociales, tanto en el interior del bloque de poder con la consolidación de la fracción productivo-exportadora del capital y la subordinación relativa de las empresas de servicios y el capital bancariofinanciero, junto a un proceso de recuperación de las PyMEs, como en relación con las clases subalternas, cuyas posiciones se fueron recomponiendo.

Asimismo, el escenario se modificó también en términos de las relaciones de fuerzas políticas, tras el avance de la lucha popular y la crisis interburguesa que signó el cambio de siglo. De este modo, el nuevo régimen de acumulación se abrió paso articulado con un conjunto de estrategias hegemónicas ligadas al proyecto político-económico de gobierno que desplegó el kirchnerismo. Un proyecto de carácter nacional-popular que recuperaba elementos del peronismo clásico, enlazados con otros ligados a la juventud de los 70 , al progresismo democrático de los 80 y el espíritu rupturista de los procesos populares latinoamericanos en curso, que hicieron de marco de alianza hacia una novedosa y potente integración regional con mayores márgenes de soberanía.

Dentro de ese cuadro de relaciones de fuerzas internacionales se rechazó el ALCA y se dio fin a los tratados con el FMI. En el interior de ese bloque popular latinoamericano, Argentina se ubicó dentro de las experiencias que, sin buscar una superación del orden capitalista, intentó delinear un proyecto de "crecimiento con inclusión social" basado en un "capitalismo serio o nacional", a partir de una estrategia de pacto populista, donde el Estado procuraba articular intereses dominantes y subalternos, forjando equilibrios inestables entre las fracciones de clase. A su vez, el populismo como lógica política operaba a partir de la confrontación establecida en la articulación de demandas que cobró lugar delimitando a un adversario trazado en torno a las figuras diversas que encarnaban el paradigma neoliberal y que templaba la propia identidad kirchnerista.

Sin embargo, se expresaron algunas continuidades respecto del régimen neoliberal que comenzaron a entrar en contradicción tanto con el funcionamiento del neo-desarrollismo como de la estrategia de construcción hegemónica en la cual se sustentaba. La elevada concentración económica dejó un esquema de relaciones de fuerzas sociales favorable al gran capital, cuyos componentes comenzaron a defeccionar del pacto social, con gran capacidad para formar precio y preservar sus ganancias en la puja distributiva, concentrar divisas y secar la plaza local de dólares o generar una corrida contra la moneda local, entre otras capacidades de veto que empezaron a ejercer sobre la política pública. También la extranjerización implicó un drenaje constante de divisas vía envío de remesas, pago de intereses y honorarios hacia las casas matrices. La reticencia inversora de la burguesía local, las afianzadas prácticas rentísticas y la tendencia a la fuga de capitales confluyeron en ese camino de externalización de activos, haciendo perder fuerza al proceso de crecimiento económico. Asimismo, la persistencia de una similar matriz productiva dependiente y la irrupción de la crisis energética, junto con el declive del precio de los commodities, reinstalaron el escenario de la restricción externa.

Así, las continuidades fueron abonando un conjunto de obstáculos macroeconómicos que comenzaron a obstruir la propuesta de desarrollo con mayor equidad. 
Los pilares del modelo productivo-exportador comenzaron a entrar en crisis: la industria se desaceleró hasta estancarse y las exportaciones comenzaron a contraerse; a su vez, ya desde 2012 se extinguió el superávit fiscal, mientras que el superávit comercial recién lo hizo en 2015. Asimismo, el proyecto nacional-popular, se vio tensionado: la extranjerización tendía a limitar el carácter nacional, mientras que la concentración amenazaba con limitar su carácter popular. La fragmentación del movimiento obrero, las limitaciones en la construcción de un poder popular alternativo, y los crecientes desgajamientos del FPV marcaron también un debilitamiento de la potencia hegemónica del kirchnerismo.

Frente a estos factores de crisis, el kirchnerismo se mantuvo firme en su estrategia inclusiva, multiplicando sus políticas expansivas y distributivas, aún a costa del deterioro de las cuentas fiscales, con el fin de sostener el consumo y la inversión pública como vía de estimulación de la demanda y el mercado interno en el contexto de un capitalismo global en crisis.

Entendemos que no fue el colapso del régimen neo-desarrollista lo que marcó el fin de esta experiencia, sino que lo que estaba en crisis era su primer modelo, el productivo-exportador, y que si bien el Gobierno dio pasos hacia un modelo de carácter propiamente nacional-popular basado en el consumo popular y el mercado interno, este trayecto quedó a medio camino. Así, la anunciada "profundización" no llegó a materializarse y el conjunto de desequilibrios comenzó a ser capitalizado por un nuevo alineamiento opositor que, surgido del seno de las clases dominantes a partir del conflicto agrario de 2008, realizó un proceso de ensayo y error hasta cristalizar en Cambiemos, como la fórmula que a nivel local expresa la estrategia de la contra-ofensiva norteamericana para recuperar su "patio trasero" y poner fin a los gobiernos populares y progresistas que disputaron su hegemonía en la región ostentando mayores márgenes de autonomía.

Las continuidades del régimen neoliberal que pervivieron en el neo-desarrollismo, sostuvieron un esquema de relaciones de fuerzas sociales favorables al capital concentrado local y transnacional creando las condiciones estructurales sobre las que se forjó la contra-ofensiva restauracionista y conservadora. A su vez, los grandes medios de comunicación actuaron lúcidamente como intelectuales orgánicos del alineamiento opositor erosionando las posiciones del kirchnerismo, articulando el descontento y dotándolo de una salida: el "cambio". Aquí también se hicieron patentes las limitaciones de la construcción hegemónica del kirchnerismo, con el desgaste natural de tres presidencias consecutivas, con serias dificultades para promocionar nuevos referentes y con un tejido organizativo importante pero no lo suficientemente fuerte para resistir al bloque de poder.

Así, Cambiemos desmontaría en poco tiempo buena parte del andamiaje de la década anterior, con la vuelta al hiper-endeudamiento y la valorización financiera, el mega-tarifazo que volvió a cambiar el esquema de precios relativos a favor de las privatizadas ahogando a los trabajadores y a las PyMEs, abatidas por la apertura comercial, con más de un millón de nuevos pobres y cientos de miles de indigentes, con más desempleo y desigualdad, profundizando de hecho todos los factores de crisis que dejaba el neo-desarrollismo, con más déficit fiscal por la 
quita de impuestos a los sectores más concentrados del capital, y creciente déficit comercial, pero con el endeudamiento externo como "parche" circunstancial, el blindaje mediático como herramienta hegemónica y la represión a la protesta como arma coercitiva. Con Cambiemos en el poder se expresa como nunca al Estado como factor de unidad política del bloque de poder: el poder político, económico, judicial y mediático funcionando en un mismo sentido en un proceso de distribución regresiva en base a la restauración del régimen neoliberal en Argentina. Es por ello que la reflexión sobre las limitaciones en materia de hegemonía y acumulación de la primera década y media del siglo XXI constituye un imperativo para la comprensión de la actualidad y un aprendizaje para el futuro.

\section{Referencias}

1. Este trabajo es parte de una investigación de largo alcance, sobre modelo de acumulación y hegemonía en la Argentina post-convertibilidad, realizada desde 2008 en el marco de las distintas becas doctorales y posdoctoral de CONICET, que a partir del ingreso a la carrera de investigador en 2017 aborda un nuevo período para el cual comienzan a delimitarse los distintos factores de análisis que se esbozan de modo exploratorio en el presente artículo.

2. Debe tenerse en cuenta que en 2002 el PBI se contrajo un $10,9 \%$.

3. Datos de desocupación según INDEC de 2017 y datos de pobreza e indigencia de CIFRA (2015).

4. La crisis mundial tuvo un severo impacto en el país a fines de 2008 y, particularmente, en 2009, con contracción de la industria y la inversión, caída de las exportaciones y aumento del desempleo llevando a un escenario de recesión económica. Frente a esta situación, el gobierno nacional diseñó un plan anti-crisis que incluyó vastos dispositivos tendientes a sostener la producción y el empleo a partir de la inversión pública en distintos rubros como estimulador económico. Para mayor detalle ver Varesi (2011).

5. Según datos INDEC, contrastando los períodos 1993-2001 vs 2002-2007, la relación IBIF/PBI pasó del 19\% al 18,4\%, Consumo privado/PBI del 68,9\% al 65,6\%, Consumo Público/PBI del 12,9\% al $21,6 \%$ mientras que Exportaciones/PBI aumentó del 9,9\% al 13,9\%.

6. Las conclusiones fueron escritas en un contexto donde CFK había ganado su reelección con el 54\% de los votos y nada parecía evidenciar ni una crisis próxima de su hegemonía ni tampoco un corte abrupto en el régimen de acumulación. Recientemente fue publicado un artículo que recoge los principales elementos de análisis de dichas conclusiones en Cuadernos del Cendes (Varesi, 2016b).

7. "El proceso de desinversión a nivel local tuvo como contracara utilidades record que luego se remitieron al exterior. Entre 1999 y 2011, YPF obtuvo ganancias por 16.450 millones de dólares y giró al exterior dividendos por 13.246 millones de dólares. En el mismo período, el patrimonio neto de la empresa se redujo 41 por ciento, mientras que la producción de petróleo cayó 43 por ciento y la producción de gas disminuyó 31 por ciento. Las cifras dejan en claro que Repsol utilizó los recursos para favorecer su expansión internacional a costa de la petrolera local, que al mismo tiempo fue reduciendo su radio de acción a la Argentina" (Krakowiak, 2016: 1).

8. Dato presentado por Zaiat (2015).

9. Datos presentados por el Centro de Despachantes de Aduana de la República Argentina.

10. Debe tenerse en cuenta, a su vez, que no se trata sólo de un problema de concentración, sino que además está atravesado por diversas asimetrías sectoriales y por el peso político que cada sector puede ejercer tanto sobre la economía como sobre el Estado, con sus representaciones corporativas.

11. Datos presentados por Porta et al. (2017).

12. Datos presentados por Porta et al. (2017).

13. Datos INDEC (2016).

14. Datos INDEC presentados por CIFRA (2016). Para 2015 toman información del primer semestre.

15. Datos INDEC presentados en el Anexo estadístico de Porta et al. (2017). 
16. Datos provistos por el Banco Mundial (2017b).

17. Datos presentados por CIFRA (2016).

18. Estuvo al frente de la ANSES entre 2002 y 2007, asumió como Intendente de Tigre en 2008 pero tomó licencia para convertirse en Jefe de Gabinete de CFK desde julio de ese año hasta el año siguiente, en que abandonó el ejecutivo nacional para reasumir como Intendente.

19. Datos presentados por CIFRA (2015; 2016).

20. Boron plantea que "en lugar de sumar fuerzas para lograr la estratégica derrota del PRO en la ciudad capital de la Argentina la conducción del FpV se refugió en un discurso fundamentalista y bajo el argumento que uno y el otro eran iguales, que Lousteau era lo mismo que Rodríguez Larreta, se abstuvieron de orientar a sus seguidores para que apoyaran a aquél para, de ese modo, descargar un golpe de nocaut al macrismo" (2016: 14-15).

\section{Bibliografía}

Banco Mundial (2017). "Exportaciones de bienes y servicios (\% del PIB). Datos sobre las cuentas nacionales del Banco Mundial y archivos de datos sobre cuentas nacionales de la OCDE". Recuperado de https://datos.bancomundial.org/indicador/NE.EXP.GNFS.ZS?locations=AR

Banco Mundial (2017b). "Industria, valor agregado (\% del PIB). Datos sobre las cuentas nacionales del Banco Mundial y archivos de datos sobre cuentas nacionales de la OCDE". Recuperado de https:// datos.bancomundial.org/indicador/NV.IND.TOTL.ZS?locations $=$ AR

Basualdo, E. (2007). "Concepto de patrón o régimen de acumulación y conformación estructural de la economía”. Documento №1, Maestría en Economía Política Argentina. Buenos Aires: FLACSO.

Boron, A. (2016). “Argentina 2016: Claves de una derrota". Cuadernos Marxistas, № 10. Buenos Aires: CEFMA.

Castellani, A. y Gaggero, A. (2017). "La relación entre el Estado y la elite económica". En A. Pucciarelli y A. Castellani (coords.). Los años del kirchnerismo. La disputa hegemónica tras la crisis del orden neoliberal. Buenos Aires. Argentina: Siglo XXI.

CEP (2008). "La industria Argentina: Balance 2003-2007. Los nuevos sectores dinámicos". Buenos Aires. Argentina: MECON.

CIFRA (2015). "Principales resultados de pobreza e indigencia 2003-2015". Informe especial. Buenos Aires. Argentina: CTA.

CIFRA (2015b). "La naturaleza política y la trayectoria económica de los gobiernos kirchneristas". Documento de trabajo $\mathrm{N}^{\circ} 14$. Buenos Aires. Argentina: CTA.

CIFRA (2016). "Informe de coyuntura n¹9". Buenos Aires. Argentina: CTA.

A. GRAMSCI (2003). Notas sobre Maquiavelo, sobre la politica y sobre el Estado moderno. Buenos Aires. Argentina: Nueva Visión.

INDEC (2016). "Intercambio Comercial Argentino. Datos provisorios de los años 2014 y 2015". Buenos Aires. Argentina: Ministerio de Hacienda.

INDEC (2017). "Encuesta Nacional a Grandes Empresas año 2015". Buenos Aires: Argentina Ministerio de Hacienda.

Krakowiak, F. (31-05-2016). "Recuerdos del saqueo". Página 12. Buenos Aires. Argentina.

Manzanelli, P. (2015). "Aportes al estudio de la formación de capital en la Argentina actual (20022012)". № 45. En Ensayos de Economía, Medellín. Colombia: Universidad Nacional de Colombia.

Porta, F. Santarcángelo, J. y Schteingart, D. (2017). "Un proyecto político con objetivos económicos. Los límites de la estrategia kirchnerista”. En A. Pucciarelli y A. Castellani (coords.). Los años del kirchnerismo. La disputa hegemónica tras la crisis del orden neoliberal. Buenos Aires. Argentina: Siglo XXI.

Poulantzas, A. (1981). Las clases sociales en el capitalismo actual. México DF. México: Siglo XXI.

Schorr, M. y Wainer, A. (2017). "La economía argentina bajo el kirchnerismo: de la holgura a la restricción externa. Una aproximación estructural”. En A. Pucciarelli.y A. Castellani (coords.). Los años del kirchnerismo. La disputa hegemónica tras la crisis del orden neoliberal. Buenos Aires. Argentina: Siglo XXI.

Schunk, R.; Rielgelhaupt, E. y Rodríguez, L. (2014). "Dilemas recurrentes del modelo de crecimiento 
distributivo en un país periférico". Realidad Económica, N2 282. Buenos Aires, Argentina: IADE. Torrado, S. (1992). Estructura social de la Argentina: 1945-1983. Buenos Aires. Argentina: Ediciones de la Flor.

Varesi, G. (2011). "Argentina 2002-2011: Neo-desarrollismo y radicalización progresista". Realidad Económica, $\mathrm{N}^{\circ}$ 264. Buenos Aires. Argentina: IADE.

Varesi, G. (2013). Modelo de acumulación y hegemonía en la Argentina post-convertibilidad, 20022008, Tesis de Doctorado, FAHCE-UNLP, Memoria Académica.

Varesi, G. (2014). "La construcción de la hegemonía kirchnerista en Argentina, 2003-2007”, en Temas y Debates, Facultad de Ciencia Política y Relaciones Internacionales de la Universidad Nacional de Rosario, año $18, \mathrm{~N}^{\circ} 28$.

Varesi, G. (2014b). "El "conflicto del campo" de 2008 en Argentina: hegemonía, acumulación y territorio", en Geograficando Revista de Estudios Geográficos, FAHCE-UNLP, Vol.10 No 2

Varesi, G. (2016). "Introducción a la perspectiva gramsciana de la hegemonía. Intelectuales, partidos y relaciones de fuerzas", Estudio introductorio de VARESI (comp.) Hegemonía y lucha política. Selección de textos de Antonio Gramsci, Buenos Aires, Luxemburg.

Varesi, G. (2016b). "Neo-desarrollismo y kirchnerismo. Aportes para un análisis conjunto del modelo de acumulación y la hegemonía en Argentina, 2002-2008", en Cuadernos del CENDES, Caracas, UCV, $\mathrm{N}^{\circ} 92$.

Zaiat, A. (2015). "Muy pocos se llevaron todo", Argentina, 20/12, Página 12.

Recibido: 01/12/2017. Aceptado: 30/ 12/2017.

Gastón Varesi, "De la crisis del régimen neo-desarrollista y la hegemonía kirchnerista al triunfo de Cambiemos". Revista Temas y Debates. ISSN 1666-0714, año 22, número 35, enero-junio 2018, pp. 1338. 